\title{
Isolation, identification and characterization of Burkholderia pseudomallei from soil of coastal region of India
}

\author{
Archana Prakash ${ }^{1}$, Duraipandian Thavaselvam ${ }^{1 *}$, Ashu Kumarr ${ }^{1}$ Ajith Kumarr ${ }^{2}$ Sonia Arora ${ }^{1}$, Sapana Tiwari ${ }^{1}$, \\ Anita Barua ${ }^{1}$ and Kannusamy Sathyaseelan ${ }^{1}$
}

\begin{abstract}
Melioidosis is an emerging infectious disease caused by a free living soil dwelling Gram-negative bacterium Burkholderia pseudomallei. The disease is endemic to most parts of Southeast Asia and northern Australia and the organism has been isolated from moist soil and water. In India clinical cases are recently reported from the states of Tamilnadu, Kerala, Karnataka, Maharashtra, Orissa, Assam, West Bengal, Pondicherry and Tripura. This study is aimed to confirm the prevalence of this important bacterial species in soil samples collected from coastal areas of Tamilnadu. Forty five soil samples from five different sites were collected from Parangipettai, Tamilnadu and screened for the presence of B. pseudomallei. The study confirmed 4 isolates as B. pseudomallei with the help of conventional bacteriological methods and molecular methods that include; $16 \mathrm{~S}$ rDNA sequencing, B. pseudomallei specific PCR, fliC gene RFLP and MALDI-TOF mass spectrometry based bacterial identification. This study reveals the prevalence and distribution of B. pseudomallei in the soil environment in coastal areas of southern India and further necessitates studies from other parts of the country. It will also be helpful to understand the distribution of B. pseudomallei and to access its epidemiological importance.
\end{abstract}

Keywords: Burkholderia pseudomallei; Ashdown agar; Melioidosis; Parangipettai; Soil isolate

\section{Introduction}

Melioidosis is caused by soil dwelling Gram-negative bacterium Burkholderia pseudomallei and is an emerging infectious disease in India. The disease is mainly endemic in Southeast Asia and northern Australia with highest number of melioidosis cases reported from Thailand. The global distribution boundaries of melioidosis continue to expand well beyond the traditionally recognized endemic regions (Currie et al., 2008). In India, clinical cases have been reported from states of Tamilnadu, Kerala, Karnataka, Maharashtra, Orissa, Assam, West Bengal, Pondicherry and Tripura. Burkholderia pseudomallei has been isolated from clinical samples like blood, sputum, pus, urine, synovial, peritoneal and pericardial fluids mostly from tertiary care hospitals located at Vellore, Tamil Nadu and Mangalore, Karnataka

\footnotetext{
* Correspondence: dtselvam@drde.drdo.in

'Division of Microbiology, Defence Research \& Development Establishment, Jhansi Road, Gwalior 474 002, India

Full list of author information is available at the end of the article
}

(Raghavan et al., 1991; Kavitha et al., 2008). The true incidence of melioidosis is not known in India and recently larger numbers of cases have been reported from the western coastal areas (Vidyalakshmi et al., 2007). Melioidosis is referred to as "a great imitator" because of its wide spectrum of clinical presentations, ranging from mild subclinical infection to fatal septicaemia that can be chronic, localized or disseminated. The infection occurs through inhalation, or skin abrasions that come in contact with contaminated soil or water. Diabetes is the most common risk factor that is associated with the disease and other risk factors include thalassaemia, alcoholism and renal impairment. Isolation of the organism from soil is required to define the epidemiology and distribution of $B$. pseudomallei, and the associated risk to humans and livestock (White, 2003; Leelarasamee, 2004). Earlier studies have shown the presence of $B$. pseudomallei in the environment based on culture of soil and water from different geographic regions, particularly from Southeast Asia and northern Australia (Strauss et al., 1969). The description

\section{实}


of $B$. thailandensis, a non-virulent but closely related species present in the soil, has made the isolation and characterization of $B$. pseudomallei from soil very challenging (Brett et al., 1998). This species has similar colony morphology characteristics to B. pseudomallei on solid media and biochemical and molecular techniques are needed to distinguish between them. The isolation of B. pseudomallei from different soil depths and during different seasons of the year has been studied, and quantitative culture of $B$. pseudomallei from soil samples has also been done in many countries previously (Smith et al., 1995; Brook et al., 1997). Recently a review for the global presence and distribution of B. pseudomallei clearly indicates that isolation of this species from soil has not been reported from India, despite its isolation from human cases (Limmathurotsakul et al., 2013). The present study was undertaken to attempt the isolation of B. pseudomallei from the coastal rice cultivating areas of Tamil Nadu, India to confirm the identity of isolates by conventional and molecular methods.

\section{Materials and methods \\ Study site and collection of samples}

The southeast coast of Parangipettai, District Cuddalore, Tamilnadu, India $\left(11^{\circ} 49^{\prime} \mathrm{N}\right.$ and $\left.79^{\circ} 76^{\prime} \mathrm{E}\right)$ was selected as the sampling site for this study. Parangipettai is $30.3 \mathrm{~km}$ from the main city of Cuddalore and $183 \mathrm{~km}$ from Chennai. The annual average rainfall of this area is approx. $945.0 \mathrm{~mm}$, mean relative humidity $57 \%$ and average temperature range between $28^{\circ} \mathrm{C}$ to $40^{\circ} \mathrm{C}$ in summer and $18^{\circ} \mathrm{C}$ to $26^{\circ} \mathrm{C}$ in the short lived winter season. Five paddy fields were chosen as study sites and the sampling was done just after the rainy season from July to Sept. 2010 at a depth of 25 to $30 \mathrm{~cm}$. Among the five paddy fields sites, sites 1 and 2 belong to Ponnanthittu village; sites 3 and 4 belong to Pinnathur village situated on the left side of the Vellar river and site 5 is situated right side of the Vellar river, near to Mutlur road (Figure 1). Ten sampling points were selected from site1 to site 4 and five sampling points from site 5 . Soil samples were collected at $100 \mathrm{~m}$ distance intervals from each other in a straight line. Approximately 100 gm of moist soil were collected from each sampling points and immediately placed into a sterile $50 \mathrm{ml}$ conical centrifuge tubes. The tubes were sealed to avoid contamination and transported to the laboratory for further processing.

\section{Soil processing and isolation}

The soil samples collected were processed for the isolation of Burkholderia pseudomallei as per the following protocol. Briefly $3 \mathrm{gm}$ of each soil sample was vigorously mixed with $3 \mathrm{ml}$ of sterile distilled water and left for overnight. $100 \mu \mathrm{l}$ of the upper surface liquid was then transferred into $5 \mathrm{ml}$ Ashdown broth with a sterile pipette and incubated at $37^{\circ} \mathrm{C}$ for $48 \mathrm{hrs}$ (Figure 2). Ashdown selective agar was modified from the recipe of Ashdown (1979) as follows: tryptone $1.5 \mathrm{~g}$, glycerol $4 \mathrm{ml}$, crystal violet $(25 \mathrm{mg} / \mathrm{ml}) 150 \mu \mathrm{l}$, neutral red $(25 \mathrm{mg} / \mathrm{ml}) 100 \mu \mathrm{l}$, gentamicin $8 \mu \mathrm{g} / \mathrm{ml}$ final concentration for $100 \mathrm{ml}$ of medium. After incubation $100 \mu \mathrm{l}$ of broth was plated onto Ashdown selective agar plates and incubated at $42^{\circ} \mathrm{C}$. The plates incubated for four days were visually inspected daily until typical colonies formed as previously described (Chantratita et al., 2007). The colonies were purified by further subculture on Ashdown agar to confirm the purity and preserved in $30 \%$ glycerol stock at $-20^{\circ} \mathrm{C}$ until further use.

\section{Biochemical and phenotypic confirmation}

Initial screening of isolates was performed according to the standard protocols followed for the identification of B. pseudomallei (Sentinel Laboratory guidelines, 2003). Two standard strains, NCTC 1688 and NCTC 10274, were used as reference type strains along with the isolates. The commercially available API 20NE (Biomerieux) was also used for the generation of biochemical profiles of all soil isolates along with standard strain (Dance et al., 1989; Amornchai et al., 2007). Results were recorded after incubation of $24 \mathrm{hr}$ to $48 \mathrm{hr}$ at $28^{\circ} \mathrm{C}$ and interpreted referring to the data interpretation table from the API 20NE manual. In vitro antibiotic susceptibility of isolates for polymyxin B (100 units/disc) and colistin ( $25 \mathrm{mcg} / \mathrm{disc})$ were also tested on Mueller-Hinton agar by the Kirby Bauer disk diffusion method (CLSI, 2007). Assimilation of L-arabinose was also tested conventionally as because it plays a key role in the discrimination of virulent $B$. pseudomallei from the nonvirulent species $B$. thailandensis (Wuthiekanum et al., 1996). The suspected isolates were further screened for yellow haze production on Francis agar for the discrimination of $B$. pseudomalle from B. cepacia (Francis et al., 2006).

\section{Molecular confirmation \\ Identification by Specific PCR}

All eight biochemically identified B. pseudomallei isolates and 59 non B. pseudomallei isolates were further identified by PCR procedures based on amplification of $23 S$ rDNA gene and the putative virulent determinant TTSS gene (Table 1). PCR was standardized with forward and reverse PCR primers and performed in a volume of $25 \mu \mathrm{l}$, the reaction mixture containing $200 \mathrm{mM}$ of each dNTP, $1.5 \mathrm{mM} \mathrm{MgCl}_{2}, 1 \times$ PCR buffer, $10 \mathrm{pmol}$ of each primer, $1 \mathrm{U}$ of Taq DNA polymerase (Fermentas) and $10 \mathrm{ng}$ DNA. The PCR cycle protocol consist of initial denaturation at $95^{\circ} \mathrm{C}$ for $6 \mathrm{~min}$ and 30 cycles of denaturation at $95^{\circ} \mathrm{C}$ for $1 \mathrm{~min}$, primer specific annealing for $1 \mathrm{~min}$ and extension at $72^{\circ} \mathrm{C}$ for $2 \mathrm{~min}$ with the final extension at $72^{\circ} \mathrm{C}$ for $10 \mathrm{~min}$. PCR products were 


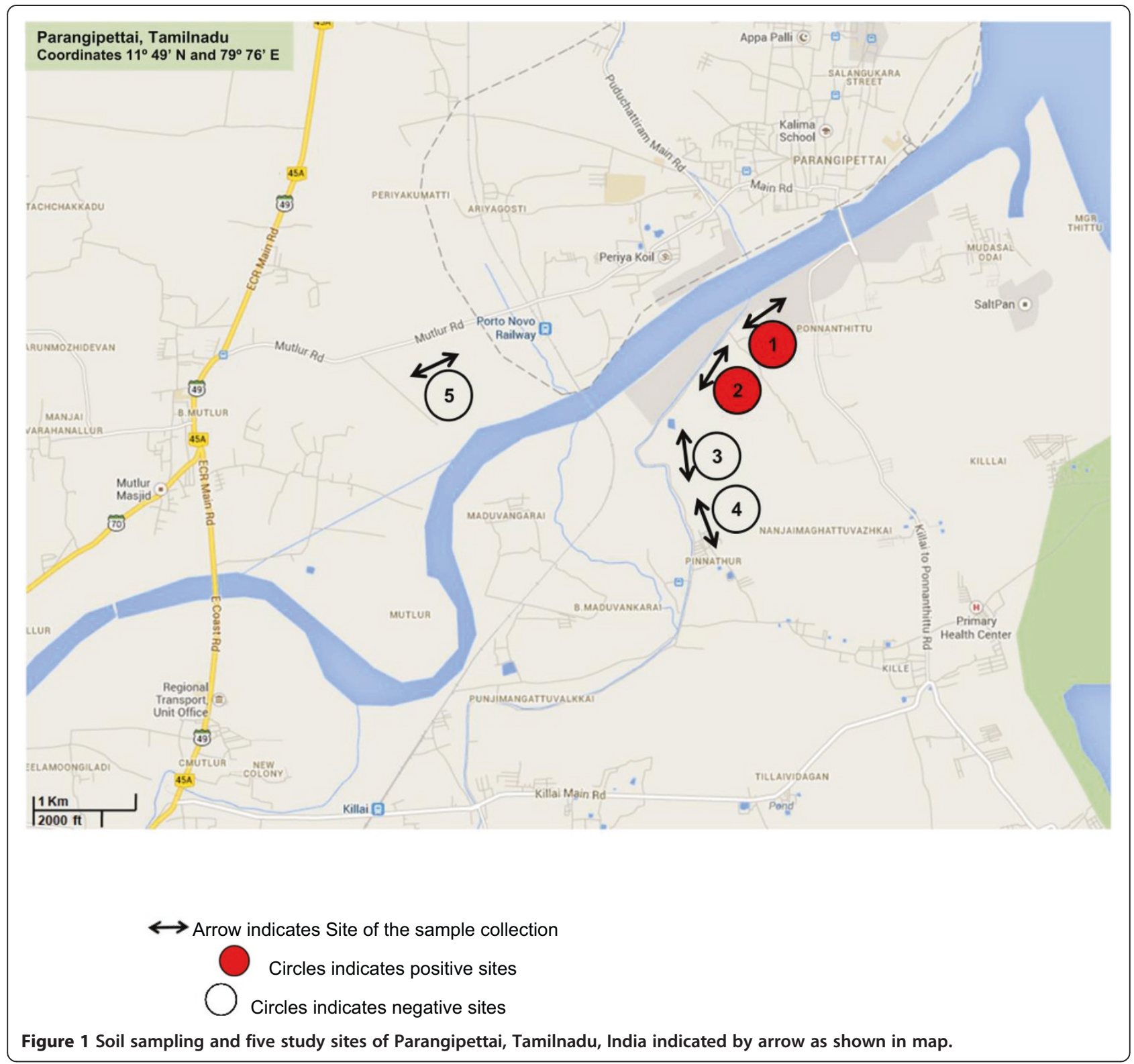

electrophoresed on $1 \%$ agarose gel and visualised under UV in an Alpha Innotech Gel Imager (Amersham Pharmacia Biotech).

\section{5 rDNA based phylogenic analysis}

$16 \mathrm{~S}$ rDNA sequencing was used to confirm PCR identified isolates and $16 \mathrm{~S}$ rDNA sequence of each isolate was BLAST analysed (Gee et al., 2003). The PCR reaction mixture for the amplification of the $16 \mathrm{~S}$ rDNA gene consisted of $200 \mathrm{mM}$ of each dNTP, $1.5 \mathrm{mM} \mathrm{MgCl}_{2}, 1 \times$ PCR buffer, $10 \mathrm{pmol}$ of each primer, $1 \mathrm{U}$ of Taq DNA polymerase (Fermentas) and $10 \mathrm{ng}$ DNA. The reaction was made up to $25 \mu \mathrm{l}$ with sterile distilled water and the cycle consisted of initial denaturation at $95^{\circ} \mathrm{C}$ for $6 \mathrm{~min}$ and 30 cycles of denaturation at $95^{\circ} \mathrm{C}$ for $1 \mathrm{~min}$, annealing at $50^{\circ} \mathrm{C}$ for $1 \mathrm{~min}$ and extension at $72^{\circ} \mathrm{C}$ for $2 \mathrm{~min}$ with the final extension at $72^{\circ} \mathrm{C}$ for $10 \mathrm{~min}$. PCR products were electrophoresed on $1.0 \%$ agarose gel and visualised under UV in a gel documentation system as above. Amplified 16S rDNA PCR products were sequenced by the dideoxy chain termination method using the Big dye Terminator v 3.1 cycle sequencing kit and Big dye X Terminator Purification kit in an ABI 10 sequencer (Applied Biosystems). The derived sequences were aligned using DNASTAR lasergene 9 Core Suit and BLAST analysis was performed for comparison with other bacterial species, sequences available in the NCBI database. A dendogram based on $16 \mathrm{~S}$ rDNA sequence 


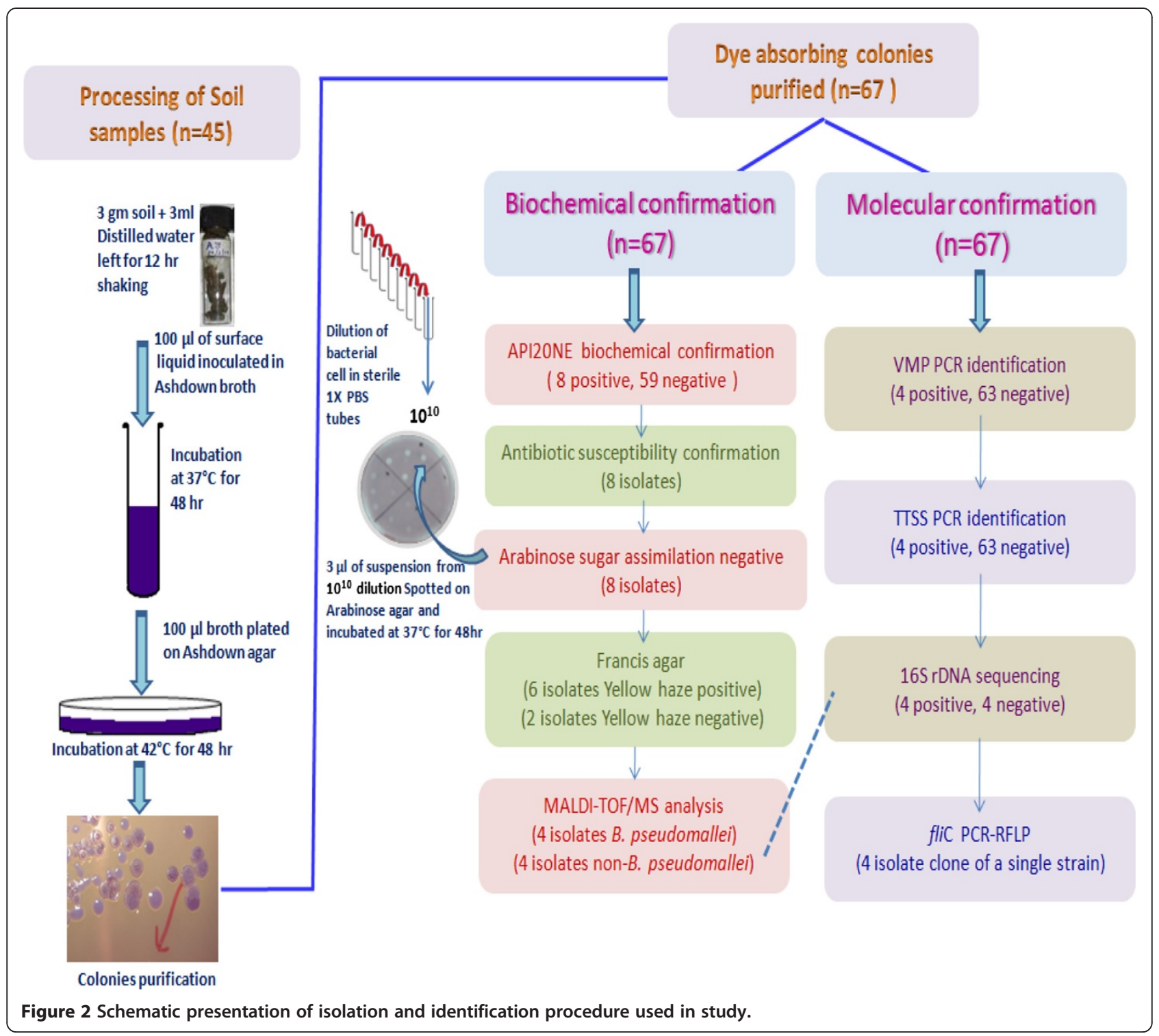

Table 1 Primers used in molecular confirmation study

\begin{tabular}{|c|c|c|c|c|}
\hline Primer name & Primer sequences & Annealing temperature & Amplification size & Purpose/Reference \\
\hline VMP 23-1-F & 5' CTITGGGTCATCCTRGA 3' & $48^{\circ} \mathrm{C}$ & $1,051 \mathrm{bp}$ & Identification (Bauernfeind et al., 1998) \\
\hline MP 23-2-R & 5' TCCTACCATGCGAGACT 3' & & & \\
\hline BPTTS1-F & 5'CGTCTCTATACTGTCGAGCAATCG 3' & $58^{\circ} \mathrm{C}$ & $548 \mathrm{bp}$ & Identification (Novak et al., 2006) \\
\hline BPTTS1-R & 5' CGTGCACACCGGTCAGTATC 3' & & & \\
\hline F8 & 5' AGTTGATCCTGGCTCAG 3' & $50^{\circ} \mathrm{C}$ & $1,488 \mathrm{bp}$ & 165 sequencing (Gee et al., 2003) \\
\hline R1492 & 5' ACCTTGTTACGACTT 3' & & & \\
\hline flic-F & 5' CTCGGATCCAACAGCAAC 3' & $52^{\circ} \mathrm{C}$ & $1,167 \mathrm{bp}$ & PCR-RFLP (Primer designed) \\
\hline flic-R & R- 5' TATTGCAGGTACCTTCAG 3' & & & \\
\hline
\end{tabular}


Table 2 Biochemical profile of standard strains and confirmed soil isolates

\begin{tabular}{|c|c|c|c|c|c|c|}
\hline \multirow[t]{2}{*}{ Substrate } & \multicolumn{2}{|c|}{ Standard strains } & \multicolumn{4}{|c|}{ Soil isolates } \\
\hline & $\begin{array}{c}\text { Burkholderia pseudomallei } \\
\text { NTCC10274 }\end{array}$ & $\begin{array}{c}\text { Burkholderia pseudomallei } \\
\text { NTCC1688 }\end{array}$ & $\begin{array}{c}\text { DRDEBPS } \\
1001 \\
\end{array}$ & $\begin{array}{c}\text { DRDEBPS } \\
1002 \\
\end{array}$ & $\begin{array}{c}\text { DRDEBPS } \\
1003 \\
\end{array}$ & $\begin{array}{c}\text { DRDEBPS } \\
1004 \\
\end{array}$ \\
\hline Nitrate & + & + & + & + & + & + \\
\hline Tryptophan & + & + & + & + & + & + \\
\hline Glucose (acidification) & + & + & + & + & + & + \\
\hline Arginine & + & + & + & + & + & + \\
\hline Urea* & - & - & - & - & - & - \\
\hline Esculin* & - & - & + & + & + & + \\
\hline Gelatin & + & + & + & + & + & + \\
\hline PNPG & - & - & - & - & - & - \\
\hline \multicolumn{7}{|l|}{ Assimilation of } \\
\hline Glucose & + & + & + & + & + & + \\
\hline Arabinose & - & - & - & - & - & - \\
\hline Mannose & + & + & + & + & + & + \\
\hline Mannitol & + & + & + & + & + & + \\
\hline N-Acetyl glucosamine & + & + & + & + & + & + \\
\hline Maltose & - & - & - & - & - & - \\
\hline Gluconate & + & + & + & + & + & + \\
\hline Caprate & + & + & + & + & + & + \\
\hline Adipate & + & + & + & + & + & + \\
\hline Malate & + & + & + & + & + & + \\
\hline Citrate & + & + & + & + & + & + \\
\hline Phenyl acetate & + & + & + & + & + & + \\
\hline
\end{tabular}

*Variable tests for B. pseudomallei.

was also constructed by the neighbor joining method using Molecular Evolutionary Genetics Analysis version 5.0 (MEGA 5) analytical software (Tamura et al., 2011).

\section{MALDI-TOF analysis for bacterial identification}

Eight biochemically identified isolates were also MALDITOF/MS analyzed for the confirmation (Table 2). For the MALDI-TOF/MS analysis, purified single colonies from a $24 \mathrm{hr}$ culture of each isolate was directly deposited on a MALDI-TOF MTP 96 target plate (Bruker Daltonik $\mathrm{GmbH}$ ), in duplicate and $1 \mu \mathrm{l}$ of $96 \%$ formic acid to each spot to inactivate the culture. The preparation was then overlaid with $1 \mu \mathrm{l}$ of matrix solution that contained a saturated solution of $\alpha$-cyano-4-hydroxycinnamic acid in $50 \%$ acetonitrile, and $2.5 \%$ trifluoroacetic acid. A total of 18 spots, two spots for the E. coli standard and $8 \times 2$ for the eight isolates were made on target plate. This matrixsample was crystallized by air-drying at room temperature for 5 minutes. Measurements were performed with a Microflex III mass spectrometer (Bruker Daltonik) equipped with a 337- nm nitrogen laser. Spectra were recorded in the positive linear mode (delay, $170 \mathrm{~ns}$; ion source 1 voltage, $20 \mathrm{kV}$; ion source 2 voltage, $18.5 \mathrm{kV}$; lens voltage, $6 \mathrm{kV}$; mass range, 2-20 kDa). Each spectrum was obtained after 240 shots in automatic mode at a variable laser power, and the acquisition time ranged from 30 to $60 \mathrm{~s}$ per spot. Data were automatically acquired using AutoXecute method of flexControl version 3.3 acquisition control software. The 2 first raw spectra obtained for each isolate were imported into Bio Typer software, version 3.0 (Bruker Daltonik $\mathrm{GmbH}$ ), and were analyzed by standard pattern matching against the 4110 mass spectra of different bacterial species as reference from the Biotyper database.

\section{Flagellin C (fliC) gene based restriction fragment length analysis}

Restriction fragment length analysis was performed on the specific PCR, 16S rDNA sequencing and MALDITOF/MS confirmed isolates to observe that whether these isolates belongs to similar strains (clone of a single strain) or belongs to different strains. The primers $f l i \mathrm{C}$ forward 5' -CTC GGA TCCAAC AGC AAC-3' and fliC reverse 5'-TAT TGC AGG TAC CTT CAG-3' were used for the amplification of the $1167 \mathrm{bp} f l i \mathrm{C}$ gene. The PCR amplification was carried out in a $50 \mu$ l reaction 
Table 3 Biochemical profiles of Ashdown grown suspected soil isolates confirmed by API20NE

\begin{tabular}{|c|c|c|c|c|c|c|c|c|c|c|c|c|c|c|c|c|c|c|c|c|}
\hline Species name & $\mathrm{NO}_{3} / \mathrm{N}_{2}$ & TRP & GLU & ADH & URE & ESC & GEL & PNG & GLU & ARA & MNE & MAN & NAG & MAL & GNT & CAP & ADI & MLT & CIT & PAC \\
\hline $\begin{array}{l}\text { Ochrobactrum } \\
\text { anthropi }(n=3)\end{array}$ & $+/+$ & - & - & - & + & - & - & - & + & + & + & - & + & + & + & + & - & + & - & - \\
\hline $\begin{array}{l}\text { Achromobacter } \\
\text { xylosoxidans }(n=5)\end{array}$ & $+/+$ & - & - & - & - & - & - & - & - & - & - & - & + & - & + & + & + & + & + & + \\
\hline $\begin{array}{l}\text { Chromobacterium } \\
\text { violaceum }(n=9)\end{array}$ & $+/+$ & - & + & + & - & - & + & - & + & - & + & + & + & - & + & + & + & + & + & + \\
\hline $\begin{array}{l}\text { Stenotrophomonas } \\
\text { maltophilia }(n=10)\end{array}$ & $+/+$ & - & - & - & - & + & + & + & + & - & + & - & + & + & - & - & - & + & + & - \\
\hline $\begin{array}{l}\text { Rizobium radiobacter } \\
(n=1)\end{array}$ & $+/+$ & - & - & - & + & + & - & + & + & + & + & + & + & + & + & - & - & + & + & - \\
\hline $\begin{array}{l}\text { Burkholderia cepacia } \\
(n=4)\end{array}$ & $+/+$ & - & + & - & - & + & + & + & + & + & + & + & + & - & + & + & - & + & + & + \\
\hline $\begin{array}{l}\text { Delftia acidovorans } \\
(n=5)\end{array}$ & $+/-$ & - & - & - & - & - & - & - & - & - & - & + & - & - & + & + & + & + & + & + \\
\hline $\begin{array}{l}\text { Ralstonia pickettii } \\
(n=3)\end{array}$ & - & - & - & - & - & - & - & - & + & - & - & - & - & - & + & + & + & + & + & - \\
\hline $\begin{array}{l}\text { Enterococcus faecalis } \\
(n=2)\end{array}$ & $+/+$ & - & + & - & - & + & - & + & - & - & - & - & - & - & - & + & - & - & + & - \\
\hline $\begin{array}{l}\text { Brevundimonas } \\
\text { vesicularis }(n=1)\end{array}$ & - & - & - & - & - & + & - & - & + & - & - & - & - & + & - & - & - & - & - & - \\
\hline $\begin{array}{l}\text { Pseudomonas luteola } \\
(n=2)\end{array}$ & $+/+$ & - & - & + & - & + & - & + & + & + & + & + & - & + & + & + & - & + & + & - \\
\hline $\begin{array}{l}\text { Comamonas } \\
\text { testosterone }(n=1)\end{array}$ & $+/+$ & - & - & - & - & - & - & - & - & - & - & - & - & - & - & + & - & + & - & - \\
\hline $\begin{array}{l}\text { Pseudomonas } \\
\text { aeruginosa }(n=5)\end{array}$ & $+/+$ & - & - & + & + & - & + & - & + & - & - & + & + & - & + & + & + & + & + & - \\
\hline $\begin{array}{l}\text { Acinetobacter Iwoffii } \\
(n=1)\end{array}$ & - & - & - & - & - & - & - & - & - & - & - & - & - & - & - & + & - & + & - & + \\
\hline $\begin{array}{l}\text { Acinetobacter } \\
\text { dentrificans }(n=2)\end{array}$ & $+/+$ & - & - & - & - & - & - & - & - & - & - & - & - & - & + & - & + & + & + & + \\
\hline $\begin{array}{l}\text { Pseudomonas } \\
\text { mendocina }(n=1)\end{array}$ & $+/+$ & - & - & + & - & - & - & - & + & - & - & - & - & - & + & + & - & + & + & - \\
\hline $\begin{array}{l}\text { Chryseobacterium } \\
\text { indologenens }(n=4)\end{array}$ & $+/+$ & + & - & - & + & + & + & - & + & - & - & - & - & + & - & - & - & - & - & - \\
\hline
\end{tabular}

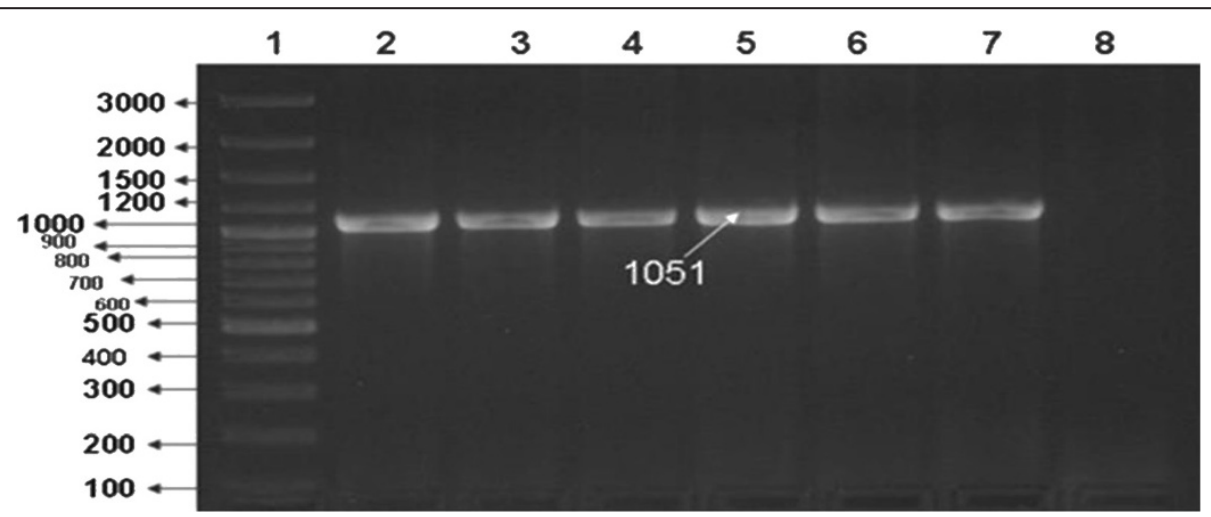

Figure 3 VMP PCR for the confirmation of isolates- Lane1: 100 bp plus Marker, Lane 2:B. pseudomalleiNTCC 10274, Lane 3: $B$. pseudomalleiNTCC 1688, Lane 4: Soil isolate DRDEBPS1001, Lane 5: DRDEBPS1002, Lane 6: DRDEBPS1003, Lane 7: DRDEBPS1004, Lane 8: Negative control. 


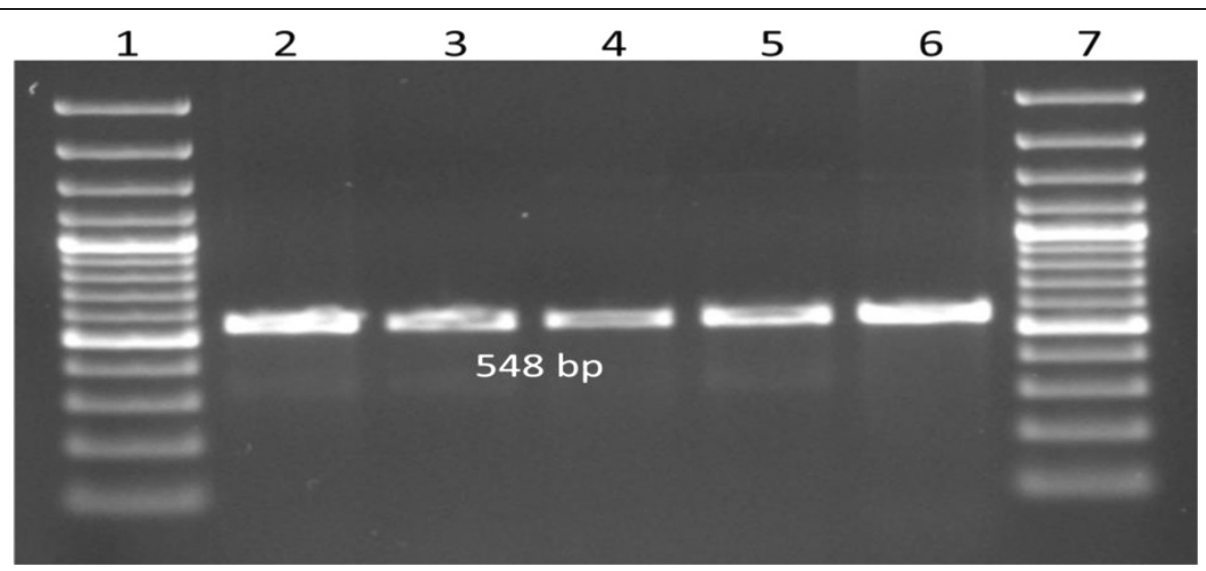

Figure 4 TTSS PCR for the confirmation of isolates- Lane1: 100 bp plus Marker, Lane 2: B. pseudomalleiNTCC 10274, Lane 3: Soil isolate DRDEBPS1001, Lane 4: DRDEBPS1002, Lane 5: DRDEBPS1003, Lane 6: DRDEBPS1004, Lane 7: 100 bp plus Marker.

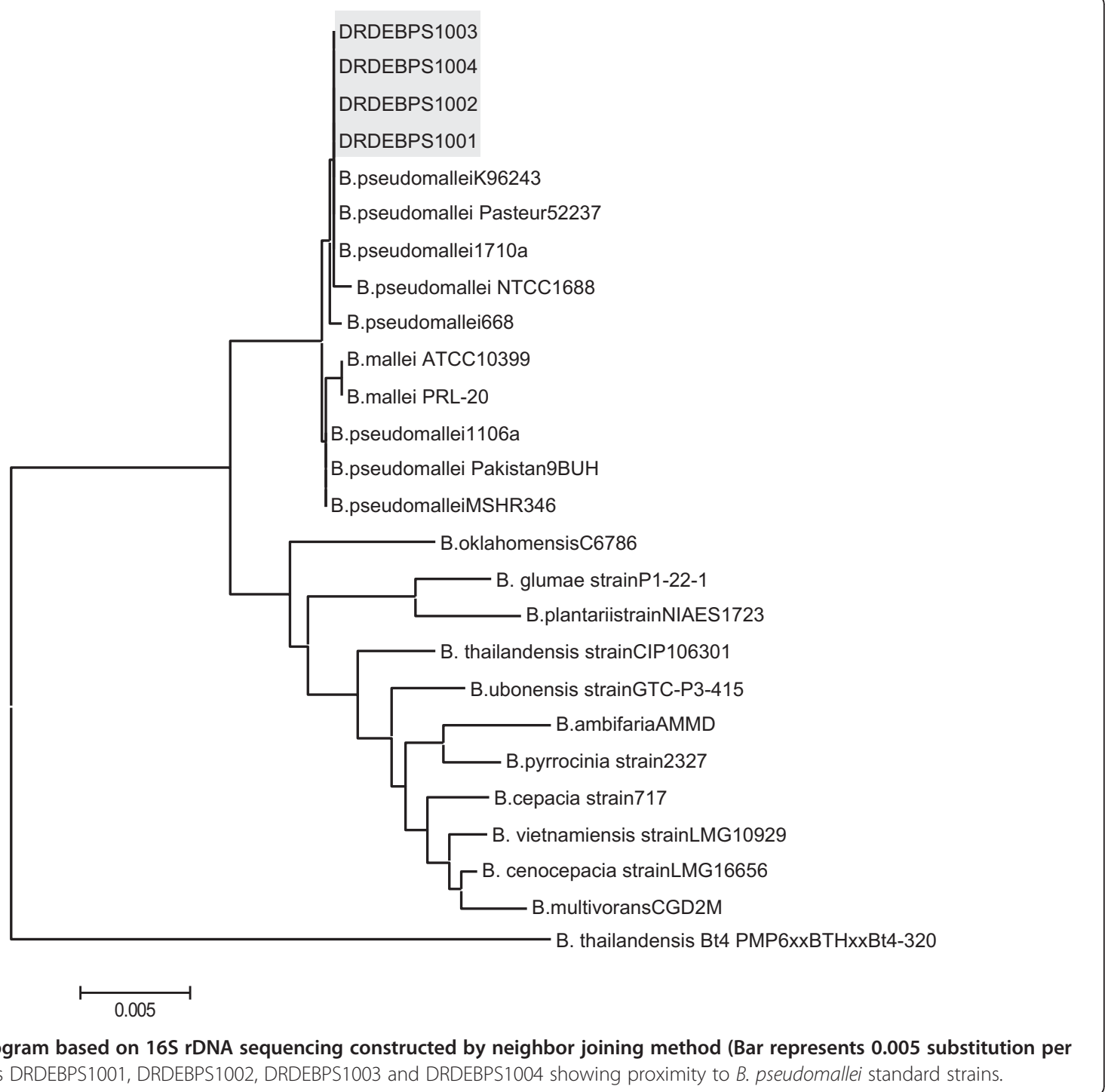

(B) 


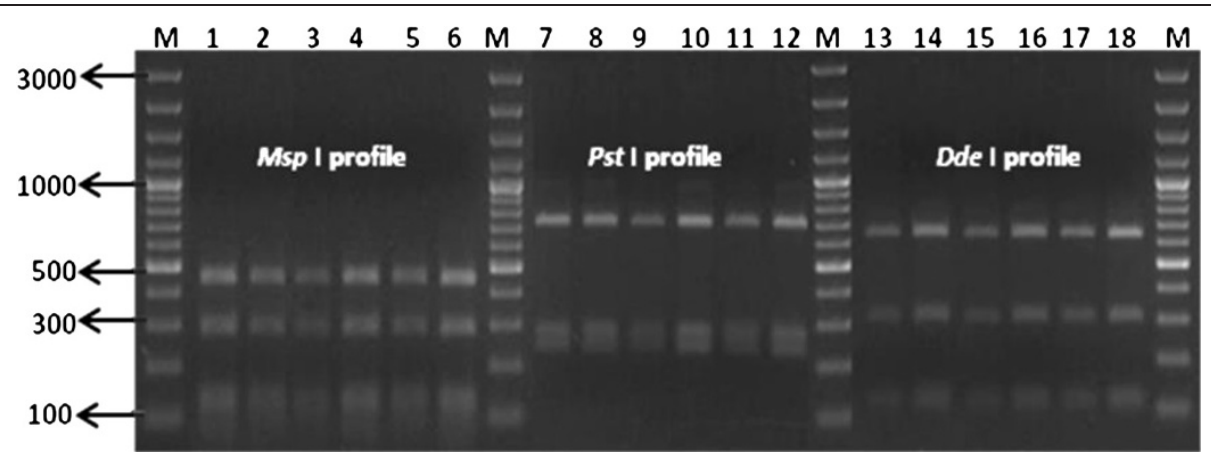

Figure 6 fliC gene Restriction patterns of isolates Lane: M 100 bp plus Marker, Lane 1, 7, 13: B. pseudomalleiNTCC 10274, Lane 2, 8, 14: B. pseudomalleiNTCC 1688, Lane 3, 9, 15: Soil isolate DRDEBPS1001, Lane 4, 10, 16: DRDEBPS1002, Lane 5, 11, 17: Soil isolate DRDEBPS1003, Lane 6,12,18: Soil isolate DRDEBPS1004.

volume with the following PCR conditions: initial denaturation at $95^{\circ} \mathrm{C}$ for $6 \mathrm{~min}$ and 30 cycles of denaturation at $95^{\circ} \mathrm{C}$ for $1 \mathrm{~min}$, annealing at $52^{\circ} \mathrm{C}$ for $1 \mathrm{~min}$ and extension at $72^{\circ} \mathrm{C}$ for 2 min with the final extension at $72^{\circ} \mathrm{C}$ for $10 \mathrm{~min}$. PCR products were purified using a gel extraction purification kit (Qiagen) and concentration was determined spectrophotometrically. Restriction digestion was performed with three restriction enzymes Dde I, Msp I and Pst I (Fermentas, fast digest). Restriction digestion reaction mixture contained $7 \mu \mathrm{l}$ of purified $f l i C$ PCR products at a conc. of $100 \mathrm{ng} / \mu \mathrm{l}$ and $1 \mathrm{U}$ of restriction enzymes. Restriction digestion reaction was carried out in $0.5 \mathrm{ml}$ tubes incubated at $37^{\circ} \mathrm{C}$ for $2 \mathrm{hrs}$ and then inactivated by keeping tubes in a dry bath at $65^{\circ} \mathrm{C}$ for 10 minutes. Then digested products were electrophoresed on $1.8 \%$ agarose gel and visualized under UV in an Alpha Innotech Gel Imager.

\section{Results \& Discussion}

From the 45 soil samples 67 isolates were suspected and selected as possible B. pseudomallei based on characteristic colonial morphology and dye absorption on Ashdown agar after incubation of $48 \mathrm{hr}$ at $42^{\circ} \mathrm{C}$. Conventional biochemical profiles of each of these 67 isolates was tested and compared with the profiles of $B$. pseudomallei NCTC 1688 and NCTC 10274. The biochemical profiles of eight isolates, namely DRDEBPS1001, DRDEBPS1002, DRDE BPS1003, DRDEBPS1004, DRDEBPS1018, DRDEBPS1019, DRDEBPS1020 and DRDEBPS1021 matched with the biochemical profile of $B$. pseudomallei with negative arabinose sugar assimilation. Interestingly all the environmental isolates were able to assimilate maltose but the standard strains could not assimilate this sugar, as also observed with most clinical isolates of $B$. pseudomallei. The biochemical profile of all these 67 isolates was determined by API 20NE and the eight isolates that were identified as $B$. pseudomallei by conventional biochemical assays were also positive by API 20NE. The identification of the remaining 59 isolates by API $20 \mathrm{NE}$ is given in Table 3 .
The antibiotic susceptibility of the 8 isolates that are biochemically consistent with $B$. pseudomallei was tested against antibiotics, polymyxin (B100 units/disc) and colistin $(25 \mathrm{mcg} / \mathrm{disc})$ and the susceptibility pattern was found similar to that of the B. pseudomallei standard strains.

These eight isolates were further processed for molecular confirmation and only four DRDEBPS1001, DRDE BPS1002, DRDEBPS1003 and DRDEBPS1004 were found positive by $B$. pseudomallei specific PCR for the truncated region of $23 \mathrm{~S}$ rDNA (VMP PCR) and TTSS gene (TTSS PCR) with the amplification of 1,051 bp and 548 bp respectively (Figures 3 and 4). Both these PCRs were also performed with the DNA of 59 isolates that were biochemically grouped as non B. pseudomallei and no amplification was observed in these isolates confirming the biochemical results. Sequencing of $16 \mathrm{~S}$ rDNA of these eight isolates confirmed that, the four isolates showed $100 \%$ homology with the NCBI database reference strains of B. pseudomallei. Isolates DRDEBPS1018, DRDEBPS 1019 were identified as Cupriavidus necator and isolates DRDEBPS1020, DRDEBPS1021 as Enterobacter cloacae. The aligned partial sequences of $16 \mathrm{~S}$ rDNA were submitted to GenBank and accession numbers JN001986, JN001987, JN001988 and JN001989 were obtained. A phylogenetic tree based on $16 \mathrm{~S}$ rDNA sequences of all four confirmed isolates was also constructed along with the standard strains of $B$. pseudomallei and other closely related species (Figure 5). The phylogenetic analysis also revealed that all four isolates closely matched with the standard strains of $B$. pseudomallei and were placed in the same clade.

The four isolates confirmed by $16 \mathrm{~S}$ rDNA sequencing were subjected to PCR-RFLP for the $f l i C$ locus and restriction profiles for three different restriction enzymes were generated. The restriction profile after digestion with Msp I produced 443, 285, 134, 123, 99, 64, 19 bp size products, Pst I digestion produced 681, 266, $220 \mathrm{bp}$ size products and Dde I enzyme digestion produced 628, 307, 123, $109 \mathrm{bp}$ size products and the restriction profile 
for all these three enzymes matched with B. pseudomallei standard strains NCTC 1688 and NCTC 10274, thereby confirming all four isolates as $B$. pseudomalle with identical restriction profiles (Figure 6).

Recently MALDI-TOF mass spectrum analysis has been considered an easy and discriminatory tool for identification of bacterial species (Lista et al., 2011). The results of MALDI-TOF mass spectrum analysis of the eight suspected isolates matched with that of the $16 \mathrm{~S}$ rDNA sequence analysis. The four isolates DRDEBPS 1001, DRDEBPS1002, DRDEBPS1003 and DRDEBPS 1004 were confirmed as $B$. pseudomallei on the basis of score values 2.601, 2.099, 2.362 and 2.047. The other four isolates had been biochemically suspected but not supported by both the PCRs were also identified by MALDI-TOF spectrum analysis as Cupriavidus necator and Enterobacter cloacae with score value of 2.112, 2.122 and 2.341, 2.241 respectively, confirming the results of the $16 \mathrm{~S}$ analysis.

The isolation of B. pseudomallei from soil is very complex as the presence of large numbers of closely related soil microflora interferes with its recovery although use of Ashdown broth and agar for the isolation of B. pseudomallei from soil samples provides some selectivity. This selectivity comes from crystal violet, neutral red and gentamicin present in the Ashdown medium. The vast majority of $B$. pseudomallei isolates are resistant to aminoglycosides due to expression of a multidrug efflux pump, thus allowing use of gentamicin for selection. This study confirms that, although this medium is useful for initial screening, many other species also grow on this medium thus interfering the recovery of $B$. pseudomallei. Francis agar is a medium that can clearly differentiate between $B$. pseudomallei and other closely related species including $B$. cepacia (Francis et al., 2006). We also analyzed all 8 suspected isolates of B. pseudomallei on Francis agar to observe the yellow haze around colonies $24 \mathrm{hr}$. Although Francis Agar was not developed for primary soil isolation of this species it can be used to confirm suspected colonies isolated from Ashdown agar. In our study the rate of isolation was found to be $5.97 \%$ as 4 isolates were confirmed as B. pseudomallei out of 67 suspected isolates from Ashdown agar and 2 isolates each were obtained from site 1 and site 2 (Figure 1). In similar soil isolation studies conducted in Malaysia and Thailand, high isolation rates were found in wet rice fields and other cleared and cultivated areas (Brett et al., 1998; Smith et al., 1995). This study reports the first isolation of B. pseudomallei from soil collected from paddy fields in the coastal region of India. The study site selected in this study fulfilled with all criteria of soil sampling which were considered as important factors in the isolation of $B$. pseudomallei. The presence of $B$. pseudomallei depends on various environmental factors that support the survival of
B. pseudomallei in soil. The presence of B. pseudomallei in soil is high during when ploughing and planting of seedlings takes place (Palasatien et al., 2008; Currie et al., 2004). The maintenance of viable bacteria in soil samples during collection, transport and storage before processing in laboratory is also an important factor for the isolation. The presence of $B$. pseudomallei needs to be initially determined by culture based methods in microbiological laboratories that require only basic equipment and provides live organisms for further confirmation by DNA based molecular methods. The isolates recovered from soil need to be compared with those recovered from clinical cases as it provides vital information on the pathogenicity and virulence of soil isolates (Currie et al., 2004). The presence of identical genetic patterns among clinical and environmental isolates suggests a link between the bacteria present in contaminated soil and the emergence of indigenous melioidosis (Chen et al., 2010). Future studies are also recommended with large number of samples collected from different geographical regions of India to study the pattern of distribution of this important bacterial species and also to correlate the epidemiological relevance of soil isolation to the occurrence of melioidosis.

\section{Conclusion}

We report the first isolation and molecular confirmation of $B$. pseudomallei from soil of paddy fields in the coastal region of India. These isolates were initially identified by conventional biochemical methods and further confirmed by advanced molecular based methods of $16 \mathrm{~S}$ rDNA sequencing, B. pseudomallei specific PCR, PCRRFLP at fliC locus and MALDI-TOF based protein profiling. This study confirms the presence of B. pseudomallei in soil in the coastal region of India. The isolation of this important bacterial species from this part of India should initiate further studies on the extent of environmental and clinical impact of melioidosis in India.

\section{Competing interests}

The authors declare that they have no competing interests.

\section{Authors' contribution}

AP carried out processing of soil samples and molecular confirmation, DT carried out data inspection, analysis of results and writing of manuscript, AK provided computational help for the alignment and phylogenic analysis of sequences, AK was responsible for collection of soil samples and transported to the lab, SA, ST AB, KS helped in experiments and data analysis. All authors read and approved the final manuscript.

\section{Acknowledgement}

Authors are thankful to Dr M. P. Kaushik, Director, DRDE Gwalior and Dr. Urmil Tuteja Head of Microbiology Division, DRDE Gwalior for their kind supports and providing facilities for this work. The financial support to Archana Prakash by UGC, Govt. of India is also acknowledged.

\section{Author details}

${ }^{1}$ Division of Microbiology, Defence Research \& Development Establishment, Jhansi Road, Gwalior 474 002, India. ${ }^{2}$ Centre for Advanced Studies in Marine Biology, Annamalai University, Parangipettai, Tamil Nadu. 
Received: 31 July 2013 Accepted: 7 August 2014

\section{Published: 16 August 2014}

\section{References}

Amornchai P, Wirongrong C, Vanaporn W, Yuvadee M, Rattanaphone P, Bart JC, Paul NN, Nguyen VC, Surasakdi W, Nicholas PJ, Peacock SJ (2007) Accuracy of Burkholderia pseudomallei identification using the API 20NE system and a latex agglutination test. J Clin Microbiol 45:3774-3776

Ashdown LR (1979) An improved screening technique for isolation of Pseudomonas pseudomallei from clinical specimens. Pathology 11:293-297

Bauernfeind A, Carsten R, Detlef M, Renate J, Ines S (1998) Molecular procedure for rapid detection of Burkholderia mallei and Burkholderia pseudomallei. J Clin Microbiol 36:2737-2741

Brett PJ, DeShazer D, Woods DE (1998) Burkholderia thailandensis sp. nov., a Burkholderia pseudomallei-like species. Int J Syst Bacteriol 48:317-320

Brook MD, Currie B, Desmarchelier PM (1997) Isolation and identification of Burkholderia pseudomallei from soil using selective culture techniques and the polymerase chain reaction. J App Microbiol 82:589-596

Chantratita N, Vanaporn W, Khaemaporn B, Rachaneeporn T, Mongkol V, Direk L, Cierakul W, Surasakdi W, Sasithorn P, White NJ, Nicholas PJ, Peacock SJ (2007) Biological relevance of colony morphology and phenotypic switching by B. pseudomallei. J Bacteriol 189:807-817

Chen YS, Lin HH, Mu JJ, Chiang CS, Chen CH, Buu LM, Lin YE, Chen YL (2010) Distribution of melioidosis cases and viable Burkholderia pseudomallei in soil: evidence for emerging melioidosis in Taiwan. J Clin Microbiol 48:1432-1434

Clinical Laboratories Standard Institute guidelines (2007) Performance Standards for Antimicrobial Susceptibility Testing. Seventeenth Informational Supplement 27(1):M100-S17

Currie BJ, Jacups SP, Cheng AC, Fisher DA, Anstey NM, Huffam SE, Huffam SM, Krause VL (2004) Melioidosis epidemiology and risk factors from a prospective whole population study in northern Australia. Trop Med Int Health 9:1167-1174

Currie BJ, Dance DA, Cheng AC (2008) The global distribution of B. pseudomallei and melioidosis; an update. Trans R Soc Trop Med Hyg 102(suppl 1):S1-S4

Dance DA, Wuthiekanun V, Naigowit P, White NJ (1989) Identification of Pseudomonas pseudomallei in clinical practice: use of simple screening tests and API 20NE. J Clin Path 42:645-648

Francis A, Aiyar S, Yean C, Naing L, Ravichandran M (2006) An improved selective and differential medium for the isolation of Burkholderia pseudomallei from clinical specimens. Dia Microbiol Inf Dis 55:95-99

Gee JE, Sacchi CT, Glass MB, De BK, Weyant RS, Levett PN, Whitney AM, Hoffmaster AR, Popovie T (2003) Use of 165 rRNA gene sequencing for rapid identification and differentiation of Burkholderia pseudomallei and B. mallei. J Clin Microbiol 41:4647-4654

Kavitha S, Satya V, Raghu SK, Ananthakrishna SB, George KV, Chiranjay M, Indira B (2008) Melioidosis - a case series from south India. Trans R Soc Trop Med Hyg 102(suppl 1):S18-S20

Leelarasamee A (2004) Recent development in melioidosis. Curr Opin Infect Dis $17: 131-136$

Limmathurotsakul D, Dance DAB, Wuthiekanun V, Kaestli M, Mayo M, Warner J, Wagner DM, Tuanyok A, Wertheim H, Cheng TY, Mukhopadhyay C, Puthucheary S, Day NPJ, Steinmetz I, Currie BJ, Peacock SJ (2013) Systematic review and consensus guidelines for environmental sampling of Burkholderia pseudomallei. PLoS Negl Trop Dis 7(3):e2105, doi:10.1371/journal.pntd.0002105

Lista F, Reubsaet Frans AG, Santis RD, Parchen RR, de Jong Ad L, Kieboom J, Laaken AL, Voskamp-Visser Al, Fillo S, Jansen HJ, Plas JV, Paauw A (2011) Reliable identification at the species level of Brucella isolates with MALDITOF-MS. BMC Microbiol 11:267

Novak RT, Glass MB, Gee JE, Gal D, Mayo MJ, Currie BJ, Wilkins PP (2006) Development and evaluation of a real-time PCR assay targeting the type III secretion system of Burkholderia pseudomallei. J Clin Microbiol 44(1):85-90

Palasatien S, Lertsirivorakul R, Royros P, Wongratanacheewin S, Sermswan RW (2008) Soil physicochemical properties related to the presence of $B$. pseudomallei. Trans R Soc Trop Med Hyg 102(suppl 1):S5-S9

Raghavan KR, Shenoi RP, Zaer F, Aiyer R, Ramamoorthy P, Mehta MN (1991) Melioidosis in India. Indian J Ped 28:184-188

Sentinel Laboratory guidelines for suspected agents of bioterrorism Burkholderia mallei and B. pseudomallei (2003) American society for microbiology. Revised 2 March 2006
Smith MD, Wuthiekanun V, Walsh AL, White NJ (1995) Quantitative recovery of Burkholderia pseudomallei from soil in Thailand. Trans R Soc Trop Med Hyg 89:488-490

Strauss JM, Groves MG, Mariappan M, Ellison DW (1969) Melioidosis in Malaysia. II Distribution of Pseudomonas pseudomallei in soil and surface water. Trans $\mathrm{R}$ Soc Trop Med Hyg 18:698-702

Tamura K, Peterson D, Peterson N, Stecher G, Nei M, Kumar S (2011) MEGA5: molecular evolutionary genetics analysis using maximum likelihood, evolutionary distance, and maximum parsimony methods. Mol Biol Evol 28(10):2731-2739

Vidyalakshmi K, Shrikala B, Bharathi B, Suchitra U (2007) Melioidosis: an underdiagnosed entity in western coastal India: a clinico-microbiological analysis. Ind J Med Microbiol 25:245-248

White NJ (2003) Melioidosis. Lancet 361:1715-1722

Wuthiekanum V, Smith MD, Dance DAB, Walsh AL, Pitt TL, White NJ (1996) Biochemical characterization of clinical and environmental isolates of Burkholderia pseudomallei. J Med Microbiol 45:408-412

doi:10.1186/2193-1801-3-438

Cite this article as: Prakash et al:: Isolation, identification and characterization of Burkholderia pseudomallei from soil of coastal region of India. SpringerPlus 2014 3:438.

\section{Submit your manuscript to a SpringerOpen ${ }^{\circ}$ journal and benefit from:}

- Convenient online submission

Rigorous peer review

- Immediate publication on acceptance

- Open access: articles freely available online

- High visibility within the field

- Retaining the copyright to your article

Submit your next manuscript at springeropen.com 